\begin{tabular}{lcl}
\hline Bentham open & The Open Petroleum Engineering \\
CrossMark & Cournal \\
\hline
\end{tabular}

RESEARCH ARTICLE

\title{
Production Analysis of Tight Sandstone Reservoir in Consideration of Stress-Sensitive Permeability
}

\author{
Yinghao Shen ${ }^{1, *}$, Xinyu Yang ${ }^{2}$ and Yuelei Zhang ${ }^{3}$ \\ ${ }^{I}$ Unconventional Natural Gas Research Institute, China University of Petroleum, Beijing, P.R. China \\ ${ }^{2}$ CNPC Bohai Drilling Engineering Company Limited, Tianjin, P.R. China \\ ${ }^{3}$ CNODC Brasil Peteoleo e Gas Ltda, Rio de Janeiro, Brazil
}

Received: August 22, 2016

Revised: February 07, 2017

Accepted: March 10, 2017

\begin{abstract}
:
Background:

Tight sandstone reservoirs play an important role in the oil industry. The permeability of tight sandstone reservoir generally has stronger stress sensitivity than that of conventional reservoir because of the latter's poor physical properties. However, the production analysis of tight sandstone reservoir did not fully considered the stress-sensitive permeability yet.
\end{abstract}

\section{Objective:}

This paper proposed a production analysis method considering the stress- sensitive permeability.

\section{Method:}

This paper firtstly investigated the stress sensitivity characteristics and the effect of stress-sensitive permeability on a tight reservoir. Decline-type curves that consider stress-sensitive permeability are then established, and a systematic analysis method was built for the production analysis to obtain the single-well controlled dynamic reserves and reservoir physical properties.

\section{Results:}

A field analysis was performed in combination with Block Yuan-284 of Changqing Oilfield. Results show that with the reduction of reservoir pressure, stress sensitivity leads to the decline in reservoir permeability and the increase in seepage resistance, thus reducing the actual single-well controlled reserve and radius.

\section{Conclusion:}

By utilizing the analysis method based on the decline curves, we can effectively predict the single-well controlled dynamic reserves of such reservoirs and evaluate the characteristic parameters of reservoirs.

Keywords: Unconventional reservoir, Stress sensitive, Tight sandstone, Production analysis, Decline-type curves.

\section{INTRODUCTION}

Unconventional oil and gas resources have become an important aspect of current oil and gas production [1, 2], and stress sensitivity is an important feature of unconventional oil and gas reservoirs, such as tight gas reservoir, tight oil reservoir, and shale gas [3 - 8]. These reservoirs have poor physical properties, and the effect of stress sensitivity is also relatively more significant. Production analysis using decline-type curves is efficient in obtaining single-well controlled reserve and reservoir physical properties. This method is more advanced than the volumetric method because of the

* Address correspondence to this author the Unconventional Natural Gas Research Institite, China University of Petroleum, $18^{\text {th }}$ Fuxue Road, Beijing, P.R. China; Tel: +86 18210117563; E-mail: shenyinghao@126.com 
strong heterogeneity, very complex pore structure, and certain particularity in the seepage mechanism of unconventional reservoir [9 - 13]. The accurate evaluation and prediction of dynamic reserves is the basis of making a reasonable development program, and it plays a vital role in the reasonable and efficient exploitation of unconventional oil and gas resources.

The current production analysis methods do not consider the effect of stress sensitivity, and thus their calculation results produce a large deviation. This article brings stress-sensitive permeability into decline-type curves to obtain a more accurate production analysis, including single-well controlled dynamic reserves, to make the calculation result correspond with the actual situation of reservoir, and to effectively guide the development of stress-sensitive oil-gas reservoirs.

\section{STRESS SENSITIVITY CHARACTERISTICS OF TIGHT SANDSTONE RESERVOIR}

Pore pressure reduces constantly in the production of oil and gas, and thus effective stress increases accordingly. The corresponding relation is expressed in the following equation [14]:

$$
S=\sigma+a p
$$

where $S$ is the total stress, $\sigma$ is the effective stress (matrix stress and pressure between particles), $a$ is the stress sensitivity correction coefficient, and is the fluid pressure or pore pressure.

Formula 1 shows that under the condition of unchanged total stress, the change in fluid pressure leads to the change in effective stress, which will correspondingly result in the change in rock physical property.

A permeability stress sensitivity experiment was conducted for the ultra-low permeability sandstone from Block Yuan-284 of Changqing Oilfield. The core belongs to the Triassic Chang-6 Reservoir Group of Ordos Basin. The main fragment component of the sandstone is feldspar lithic sandstone, which is fine-medium grain and very fine-fine grain. The stress sensitivity characteristics of sandstone were analyzed in the research area. The confining pressure was maintained, and the displacement pressure was changed to simulate the process in which the formation rock was compressed during exploitation. The stress sensitivity experiment was conducted using eight cores. Fig. (1) presents the curves of $k / k_{i}$ changing with pore pressure, where $k / k_{i}$ is the ratio of permeability and initial permeability under different pore pressure states. Fig. (1) also illustrates the experiment results. We can fit the results with the exponential law curves in which the fitting compliance degrees are all above 0.9 .

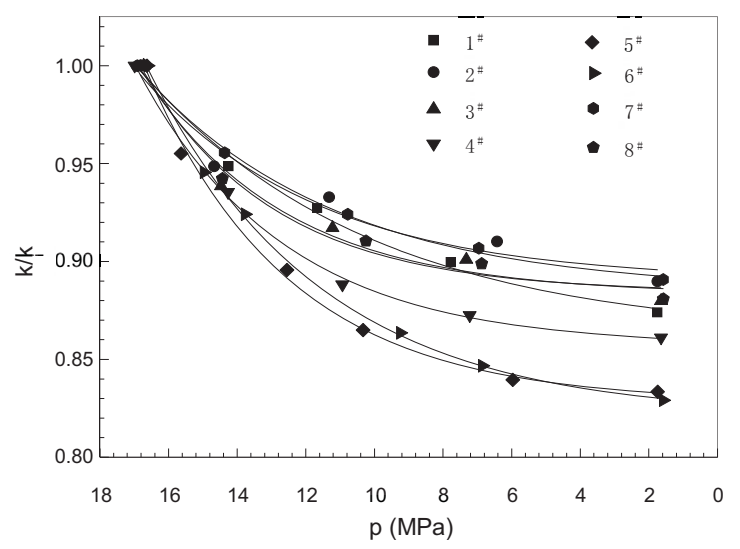

Fig. (1). Permeability stress-sensitive experiment results for chang-6 tight sandstones.

\section{TYPICAL DECLINE CHART CONSIDERING STRESS-SENSITIVITY OF PERMEABILITY}

Blasingame's decline-type curve $[15,16]$ is an important method developed on the basis of Fetkovich's decline-type curve [17 - 19] for production data analysis to evaluate single-well controlled dynamic reserves and reservoir parameters. However, to the best of our knowledge, this method currently does not consider the effect of stress sensitivity. In this study, we established a physical and mathematical model that considers stress-sensitive permeability to obtain a new series of decline-type curves that allow fr the stress-sensitivity of permeability. 
Assuming the presence of a vertical well with a circular reservoir (Fig. 2), the formation and the fluid satisfy the following conditions:

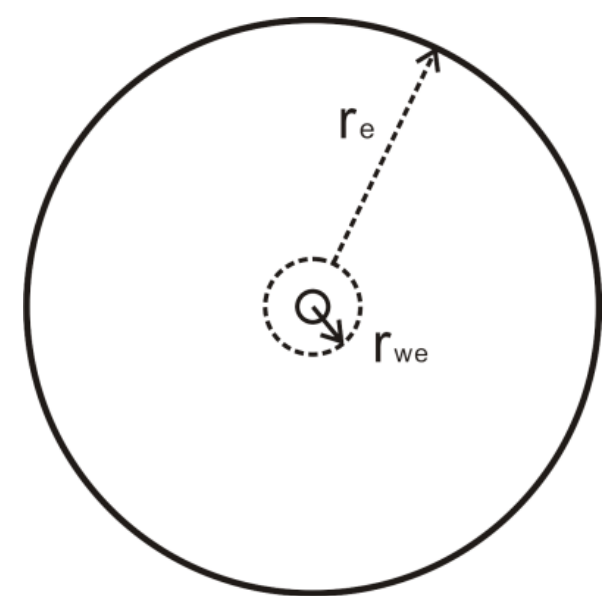

Fig. (2). Schematic Diagram of a Vertical Well in a Circular Closed Formation.

1. The reservoir is homogeneous and has a uniform thickness of $h$.

2. The original formation pressure is $P_{i}$.

3. The oil well runs throughout the whole reservoir with a wellbore radius of $r_{w}$ and constant production rate $q$.

4. The outer boundary of the reservoir is closed, and the radius of the outer boundary is $r_{e}$.

5. Permeability presents an exponential change law with pore pressure.

6. The formation fluid is Newtonian fluid.

7. The effect of capillary force, temperature, and gravity is ignored.

The basic flow equation of a homogeneous reservoir is

$$
\frac{1}{r} \frac{\partial}{\partial r}\left(r k \frac{\partial p}{\partial r}\right)=\frac{\phi \mu C_{t}}{3.6 \times 10^{-3}} \frac{\partial p}{\partial t} .
$$

When the permeability's change in pressure follows an exponential law, the permeability modulus is effective in characterizing the permeability variation law. The relation of permeability change with effective stress can be expressed as follows [20]:

$$
\gamma=\frac{1}{k} \frac{f k}{f p}
$$

where $\gamma$ is the permeability modulus of $1 \mathrm{MPa}$.

The integral for Equation (3) is

$$
k=k_{i} e^{-\gamma\left(p_{i}-p\right)}
$$

where $k_{i}$ is the reservoir permeability under the original formation pressure, $\mathrm{mD}$.

Equation (4) is the expression of the exponential change law of permeability with pressure.

By bringing (4) into (2), we obtain the following eq:

$$
\frac{1}{r} \frac{\partial}{\partial r}\left(r \frac{\partial p}{\partial r}\right)+\gamma\left(\frac{\partial p}{\partial r}\right)^{2}=\frac{\varphi \mu C_{t}}{3.6 k_{i}} e^{\gamma\left(p_{i}-p\right)} \frac{\partial p}{\partial t}
$$

The above formula is the basic percolation differential equation of a tight sandstone reservoir that considers the stress-sensitive effect of permeability. The following dimensionless variables are introduced: 


$$
\begin{gathered}
p_{D}=\frac{k_{i} h}{1.842 q \mu B} \Delta p(p) . \\
t_{D}=\frac{3.6 \times 10^{-3} k_{i} t}{\varphi \mu C_{t} r_{w}^{2}} . \\
r_{D}=\frac{r}{r_{w}} .
\end{gathered}
$$

The following dimensionless permeability modulus is defined as:

$$
\gamma_{D}=\frac{1.842 q \mu B}{k_{i} h} \gamma
$$

According to flow mechanics theory, the mathematical model of a homogeneous closed reservoir that considers stress sensitivity can be established.

The flow control equation is:

$$
\frac{1}{r_{D}} \frac{\partial}{\partial r_{D}}\left(r_{D} \frac{\partial p_{D}}{\partial r_{D}}\right)-\gamma_{D}\left(\frac{\partial p_{D}}{\partial r_{D}}\right)^{2}=e^{\gamma_{D} p_{D}} \frac{\partial p_{D}}{\partial t_{D}}
$$

The initial conditions are expressed as:

$$
p_{D}\left(r_{D}, 0\right)=0
$$

The internal boundary are expressed as:

$$
\begin{gathered}
C_{D} \frac{d p_{w D}}{d t_{D}}-\left(r_{D} e^{-\gamma_{D} p_{D}} \frac{\partial p_{D}}{\partial r_{D}}\right)_{r_{D}=1}=1 \\
p_{w D}=\left[p_{D}-S r_{D} e^{-\gamma_{D} p_{D}} \frac{\partial p_{D}}{\partial r_{D}}\right]_{r_{D}=1}
\end{gathered}
$$

The external boundary conditions are expressed as:

$$
\left.\frac{\partial p_{D}}{\partial r_{D}}\right|_{r_{D}=R_{D}}=0
$$

To calculate the above model, we used the perturbation technique for calculation and introduced the transformation relation as follows:

$$
p_{D}\left(r_{D}, t_{D}\right)=-\frac{1}{\gamma_{D}} \ln \left[1-\gamma_{D} \eta_{D}\left(r_{D}, t_{D}\right)\right]
$$

The following perturbation techniques are applied as follows:

$$
\begin{gathered}
\eta_{D}=\eta_{0 D}+\gamma_{D} \eta_{1 D}+\gamma_{D}^{2} \eta_{2 D}+\cdots \\
\frac{1}{1-\gamma_{D} \eta_{w D}}=1+\gamma_{D} \eta_{w D}+\gamma_{D}^{2} \eta_{w D}^{2}+\cdots
\end{gathered}
$$




$$
\begin{gathered}
-\frac{1}{\gamma_{D}} \ln \left(1-\gamma_{D} \eta_{D}\right)=\eta_{D}+\frac{1}{2} \gamma_{D} \eta_{D}^{2}+\cdots \\
-\frac{1}{\gamma_{D}} \ln \left(1-\gamma_{D} \eta_{w D}\right)=\eta_{w D}+\frac{1}{2} \gamma_{D} \eta_{w D}^{2}+\cdots
\end{gathered}
$$

Given the small dimensionless permeability modulus, the zero-order perturbation solution is used. Thus, Equations (10-14) are expressed as follows:

$$
\begin{gathered}
\frac{1}{r_{D}} \frac{\partial}{\partial r_{D}}\left(r_{D} \frac{\partial \eta_{0 D}}{\partial r_{D}}\right)=\frac{\partial \eta_{0 D}}{\partial t_{D}} \cdot \\
\eta_{0 D}\left(r_{D}, 0\right)=0 \\
C_{D} \frac{d \eta_{0 w D}}{d t_{D}}-\left(r_{D} \frac{\partial \eta_{0 D}}{\partial r_{D}}\right)_{r_{D}=1}=1 . \\
\eta_{0 w D}=\left[\eta_{0 D}-S r_{D} \frac{\partial \eta_{0 D}}{\partial r_{D}}\right]_{r_{D}=1} . \\
\left.\frac{\partial \eta_{0 D}}{\partial r_{D}}\right|_{r_{D}=R_{D}}=0 .
\end{gathered}
$$

By conducting the Laplace transform for Equation (20), its Laplace spatial solution can be obtainedas:

$$
\begin{gathered}
\bar{\eta}_{0 w D}=\frac{E\left(r_{D}=1\right)+S \sqrt{g} F\left(r_{D}=1\right)}{g\left\{\sqrt{g} F\left(r_{D}=1\right)+C_{D} g\left(E\left(r_{D}=1\right)+S \sqrt{g} F\left(r_{D}=1\right)\right)\right\}} . \\
E\left(r_{D}\right)=\frac{I_{0}\left(\sqrt{g} r_{D}\right) K_{1}\left(\sqrt{g} R_{D}\right)+K_{0}\left(\sqrt{g} r_{D}\right) I_{1}\left(\sqrt{g} R_{D}\right)}{I_{1}\left(\sqrt{g} R_{D}\right)} . \\
F\left(r_{D}\right)=\frac{-I_{1}\left(\sqrt{g} r_{D}\right) K_{1}\left(\sqrt{g} R_{D}\right)+K_{1}\left(\sqrt{g} r_{D}\right) I_{1}\left(\sqrt{g} R_{D}\right)}{I_{1}\left(\sqrt{g} R_{D}\right)} .
\end{gathered}
$$

In the above functions, $K_{O}$ and $K_{l}$ are a zero-order and a first-order modified Bessel function, respectively, $g$ is the Laplace Variable, $L^{-1}$ is the Laplace inverse transform, and $O\left(\gamma_{D}\right), \eta_{w D}$ is the allowance above zero-order solution.

By transforming the above analytical solution into a real spatial solution through the Stehfest inversion algorithm, we obtained $\boldsymbol{P}_{w \boldsymbol{D}} \sim \boldsymbol{t}_{\boldsymbol{D}}$. A typical decline-type curve mainly includes the decline-type curve dimensionless production proposed by Fetkovich, $\boldsymbol{q}_{\boldsymbol{D} d}$, the dimensionless material balance time $\boldsymbol{t}_{\boldsymbol{D} \boldsymbol{d}}$ proposed by Blasingame, and the dimensionless production integral and its derivative proposed by McCray, $\boldsymbol{q}_{\boldsymbol{D} d i}$ and $\boldsymbol{q}_{\boldsymbol{D i d}}$.

The decline-type curve dimensionless production and time are defined as follows:

$$
\begin{gathered}
t_{D d}=\frac{2}{\left[r_{e D}^{2}-1\right]\left[\ln r_{e D}-\frac{1}{2}\right]} t_{D} \\
q_{D d}=\left[\ln r_{e D}-\frac{1}{2}\right] q_{D}
\end{gathered}
$$


Here, $r_{w e}=r_{w} \cdot e^{-s}$.

The auxiliary drawing function generally includes the dimensionless production integral and its derivative proposed by McCray. It is introduced for practical application and is conducive to improving the efficiency and accuracy of field engineers to explain and analyze production data. In actual use, the method of fitting three groups of data simultaneously is generally adopted to obtain the best fitting effect.

The following is the dimensionless production integral:

$$
q_{D d i}=\frac{N_{p D d}}{t_{D d}}=\frac{1}{t_{D d}} \int_{0}^{t_{D d}} q_{D d}(\tau) d \tau .
$$

The following is the dimensionless production integral derivative:

$$
q_{\text {Ddid }}=-\frac{d q_{D d i}}{d \ln \left(t_{D d}\right)}=-t_{D d} \frac{d q_{D d i}}{d t_{D d}} .
$$

By drawing $q_{D d} \sim t_{D d}, q_{D d i} \sim t_{D d}$ and $q_{D d i d} \sim t_{D d}$ on the log-log plot, decline-type curves for vertical wells in homogeneous reservoirs of stress-sensitive reservoir are formed.

Fig. (3) presents the decline-type curve under different dimensionless permeability moduli $\gamma_{D}$ when the dimensionless reservoir radius $r_{e D}$ is 5000, and the values of $\gamma_{D}$ are $0,0.0015,0.003$, and 0.0045 respectively. The difference between curves in the unsteady stage in the figure is small, and it is mainly in the pseudo steady stage. The curves are shown when $\gamma_{D}$ is $0,0.0015,0.003$, and 0.0045 from right to left.

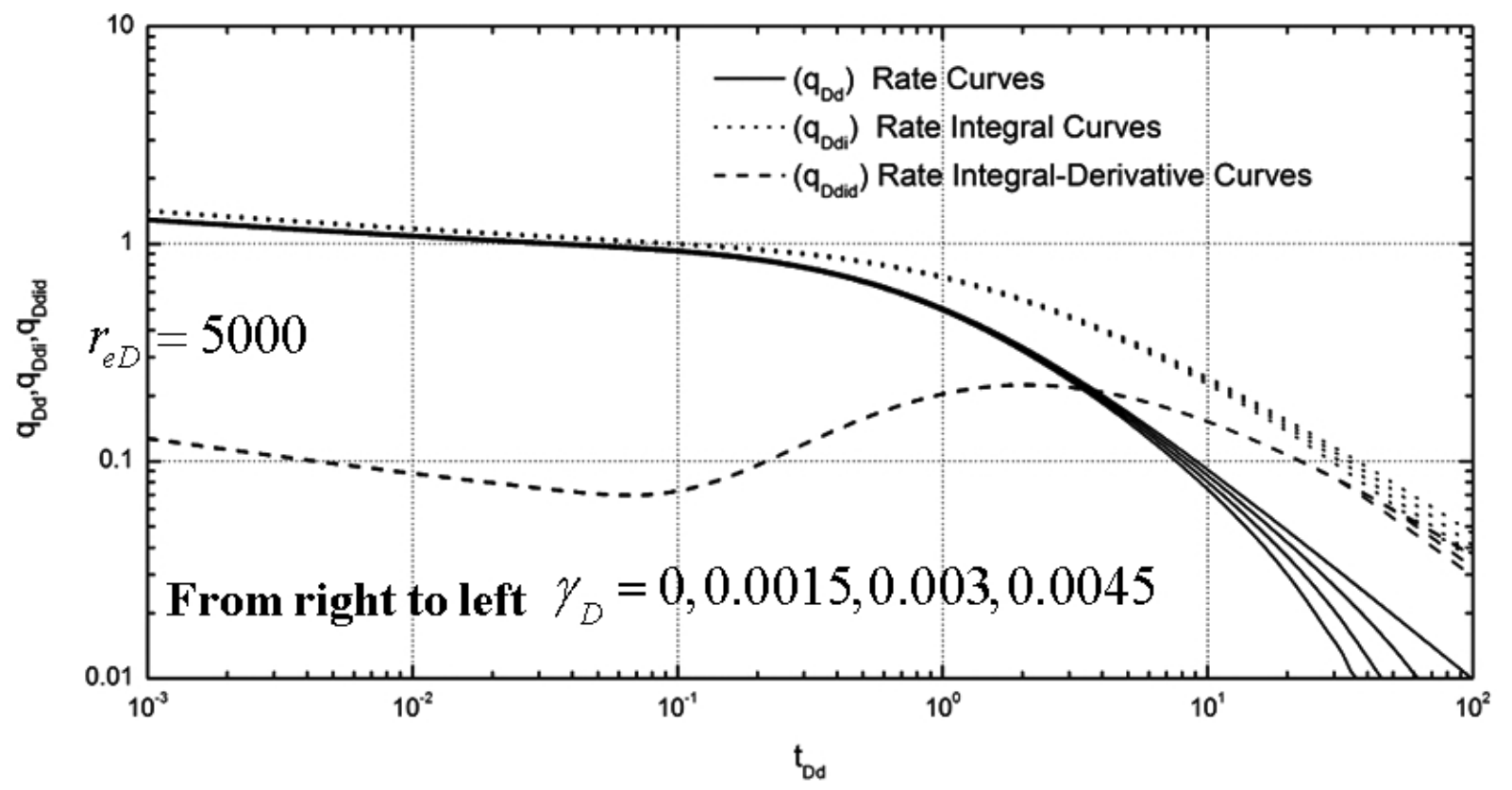

Fig. (3). Decline-type Curves for Vertical Wells in Stress-sensitive Reservoirs (Different Permeability Moduli).

Fig. (4) illustrates the decline-type curves under different dimensionless reservoir radii $r_{e D}$ when the dimensionless permeability modulus $\gamma_{D}$ is 0.003 and the values of $r_{e D}$ are 200, 500, 2000, and 5000, respectively. The difference exists both in the unsteady stage and in the quasi-steady stage. The curves are shown when $r_{e D}$ is 200,500,2000, and 5000 from top to bottom.

Figs. (3) and (4) summarize the following basic laws of the decline-type curves for vertical wells in stress-sensitive reservoirs: 


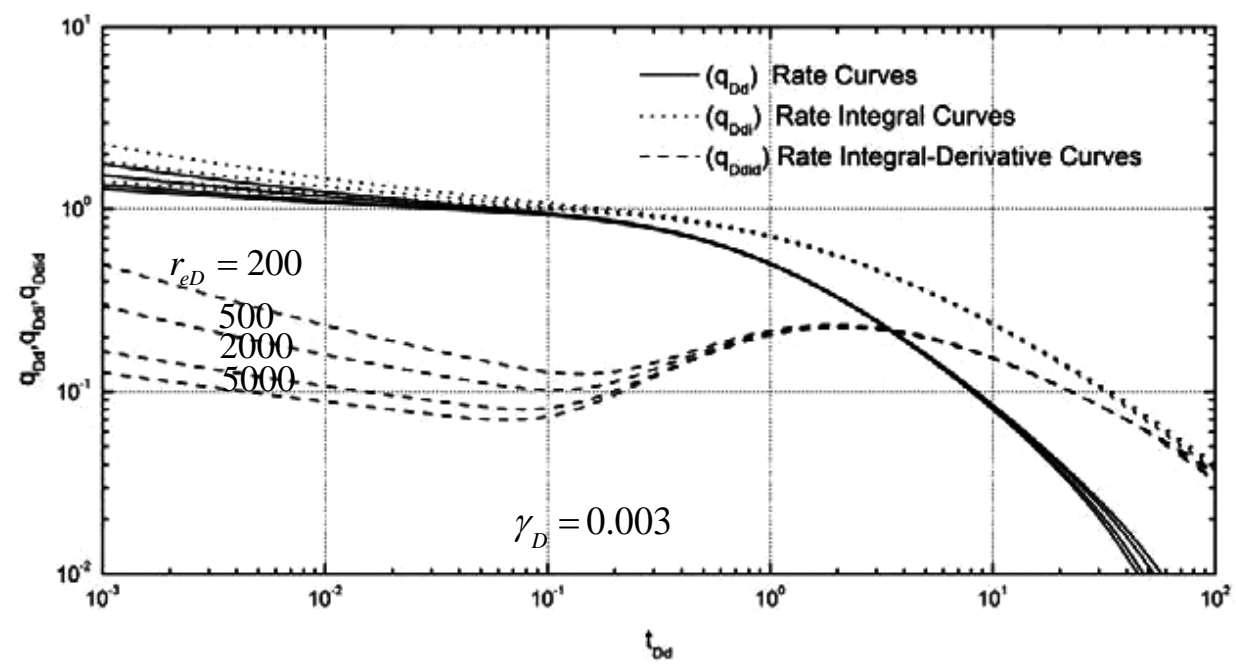

Fig. (4). Decline-type Curves for Vertical Wells in Stress-sensitive Reservoirs (Different Reservoir Radii).

1. Stress-sensitive permeability affects the decline-type curves, mainly those existing in the pseudo steady stage.

2. Stress-sensitive permeability not only affects the production curve patterns but also the production integral and production integral derivative curve to a certain extent.

3. After the curve reaches the pseudo steady state when stress sensitivity occurs, the production curve slope of the pseudo steady state for the conventional reservoir does not follow -1 any longer. The permeability is reduced because of the effect of stress sensitivity, and thus production decreases within the scope of discussion time.

4. Under the same reservoir radius, the lowering degree of the curve increases with the increase in permeability modulus. Therefore, when other conditions are the same, the effect on production and the declining range of production becomes greater with the increase in stress-sensitive degree.

5. Under the same dimensionless permeability modulus, the larger the dimensionless radius of the reservoir is, the greater is the lowering degree. That is, the effective transformation of the near-well-bore area can reduce the effect of stress sensitivity on the production.

\section{INSTANCE ANALYSIS}

An instance analysis was conducted by selecting a well in Block Yuan 284 that belongs to Ordos Basin. Block Yuan 284's purpose of horizon is the Chang-6 formation. The effective thickness of this well was 10.94 m, with porosity being 0.13 , irreducible water saturation being $43 \%$, and well radius being $0.1 \mathrm{~m}$. Its production history is illustrated in Fig. (5). The history of this well was studied first. No other operation measures wereadopted after the fracturing production of this well. Its production and pressure data were monitored daily that are representative of relatively high accuracy and good correlation (Fig. 5). The water injection enhancement productivity effect was poor, pressure and production declined with time, and the oil well remained at the depletion development state.

This well does not undergo unstable pressure testing after being put into production. Therefore, we mainly used its production data to judge the model as shown in Fig. (6).

The basic model characteristics are as follows:

- Pseudo-steady characteristicsare observed. The tightness of reservoir leads to poor flowability and a very slow effect of the water injection well. The dynamic response characteristics indicate that this well does not take effect, and thus the oil well gradually achieves the quasi-steady state with no peripheral pressure response characteristics.

- Hydraulic fracture characteristicshave been observed. The flow characteristics of the non-steady stage do not conform to the characteristics of the hydraulic fractured well. Although fracturing production is made for this well, the role of fractures in this well is to improve the near-well-bore permeability because of poor reservoir permeability. The physical property of the reservoir periphery is relatively poor, and it is a common feature of 
this well area that can be observed from the unstable pressure testing curve of similar wells in this well area.

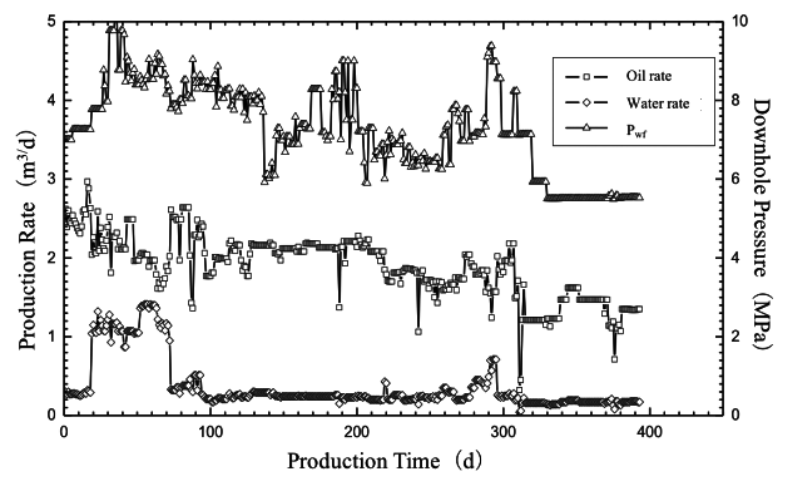

Fig. (5). Production History of the Target Well.

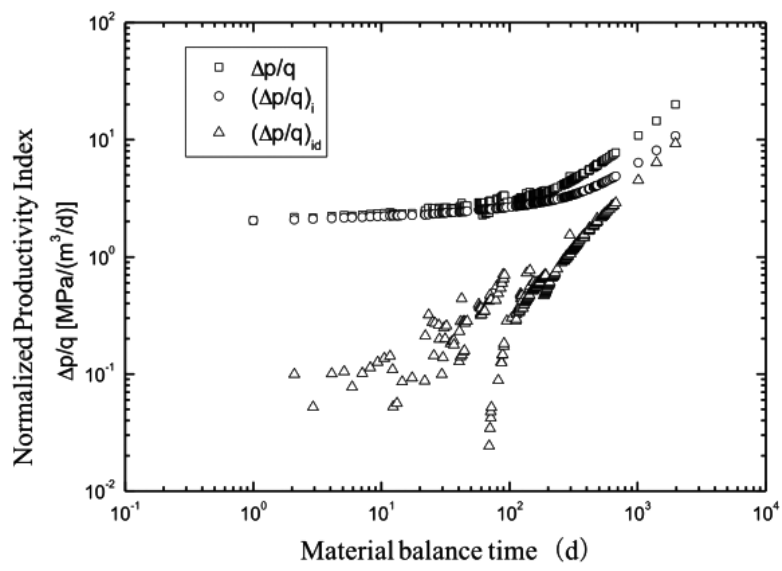

Fig. (6). Curves for the Normalized Productivity Index Function vs. Material Balance Time.

To sum up, the basic model of this well is a vertical well within a stress-sensitive closed reservoir. This well can be the model of a vertical well within a stress-sensitive closed reservoir. Through the exponential curve fitting, we obtained its permeability modulus of $0.0097(1 / M P a)$. The dimensionless permeability modulus of 0.0031 was calculated by Equation (7), to select a reasonable decline chart series from it.

To calculate the material balance time, the material balance time of the oil well is defined as follows:

$$
t_{c}=\frac{N}{q} .
$$

The calculated normalized production, production integral, and its derivative are defined as follows:

Normalized production

$$
\frac{q}{\Delta p}=\frac{q}{p_{i}-p_{w f}}
$$

Production integral (defined as the average production of well at a certain time) 


$$
\left(\frac{q}{\Delta p}\right)_{i}=\frac{\int_{0}^{t_{c}} \frac{q}{\Delta p} d t_{c}}{t_{c}}
$$

Production integral derivative

$$
\left(\frac{q}{\Delta p}\right)_{i d}=\frac{d\left(\frac{q}{\Delta p}\right)_{i}}{d \ln t_{c}}=\frac{d\left(\frac{q}{\Delta p}\right)_{i}}{d t_{c}} t_{c}
$$

A log-log plot was drawn for the curve of three production functions versus material balance time, with its coordinate scale, the same as that of the typical decline chart, and a typical decline chart with $\gamma_{D}$ equal to 0.003 was used. Through fitting, the production curve can be better fitted with a typical decline-type curve with a dimensionless reservoir radius $r_{e D}$ equal to 200 (Fig. 7).

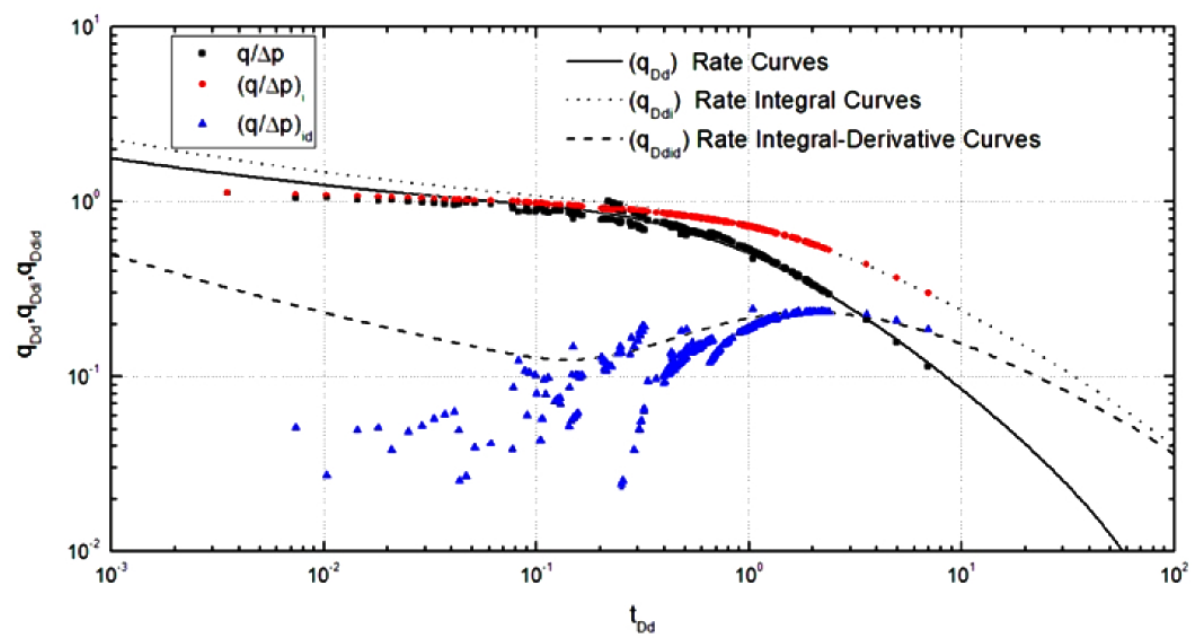

Fig. (7). Fitting Curve of the Typical Decline-type Chart.

The following fitting parameters can be obtained through fitting:

$r_{e D}=200$

$\left(t_{D d}\right)_{M P}=1.0,\left(t_{c}\right)_{M P}=6000(h)$

$\left(q_{D d}\right)_{M P}=1.0,\left(q_{\delta} / \Delta_{p}\right)_{M P}=0.38\left(m_{3} /(d M P a)\right)$

The typical curve analysis and calculation result are as follows:

Single-well controlled dynamic reserves

$$
N=\frac{0.042}{c_{t}} \frac{\left(t_{c}\right)_{M P}}{\left(t_{D d}\right)_{M P}} \frac{\left(q_{o} / \Delta p\right)_{M P}}{\left(q_{D d}\right)_{M P}}=3.42\left(10^{4} \mathrm{~m}^{3}\right) .
$$

Single-well controlled dynamic reserves expressed by quality

$$
N^{\prime}=\frac{0.042 \rho_{o}}{c_{t}} \frac{\left(t_{c}\right)_{M P}}{\left(t_{D d}\right)_{M P}} \frac{\left(q_{o} / \Delta p\right)_{M P}}{\left(q_{D d}\right)_{M P}}=2.98\left(10^{4} t\right)
$$

Reservoir discharge area 


$$
A=\frac{N B_{o}}{\phi h\left(1-S_{w i}\right)}=0.0463\left(\mathrm{~km}^{2}\right)
$$

Equivalent control radius

$$
r_{e}=\sqrt{A / \pi}=121.40(m)
$$

Original effective permeability

$$
k_{i}=\left(\frac{q / \Delta p}{q_{D d}}\right)_{m}\left(\frac{1.842 B \mu}{h}\right)\left(\ln \left(\frac{r_{e}}{r_{w e}}\right)_{m}-\frac{1}{2}\right)=0.51(m D) .
$$

Skin coefficient

$$
s=-\ln \left[\left(r_{e} / r_{e D}\right) / r_{w}\right]=-2.01 .
$$

After the model and the parameters were determined, the production history was required to be fit to verify the correctness of the model and the parameters. The well is a vertical well model within a stress-sensitive closed reservoir, and the basic parameters for fitting have been determined through the chart. The history fitting curve is presented in Fig. (8).

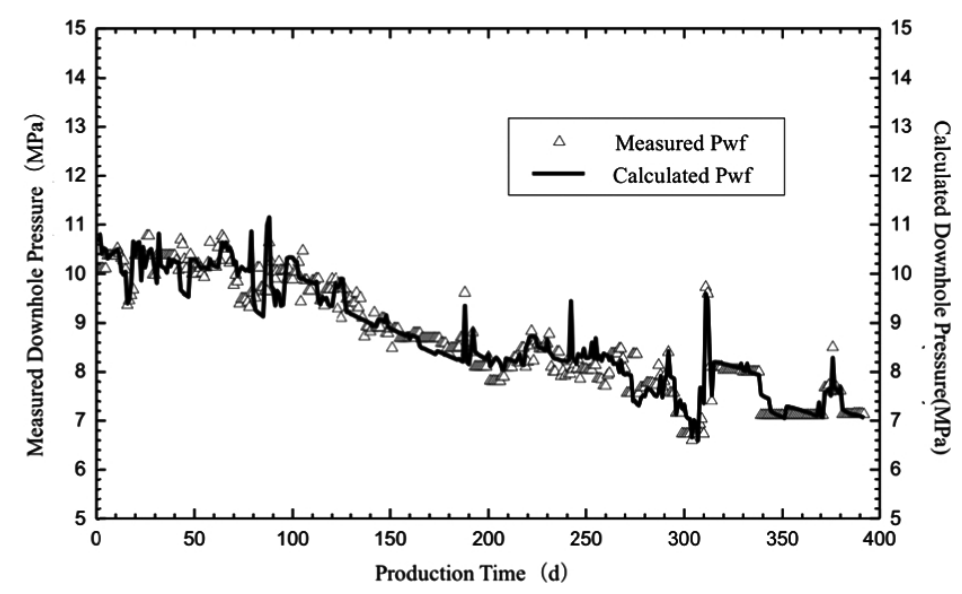

Fig. (8). Production History Fitting Curve.

Fig. (8) indicates that the fitting degree is high, and thus the adopted model and parameters have high credibility and can correctly reflect the actual status of the oil well.

\section{CONCLUSION}

1. The permeability of Chang-6 tight sandstone in Block Yuan-284 of Changqing Oilfield had significant stress sensitivity characteristics, and thus stress-sensitive permeability needed to be considered in the analysis of reservoir engineering to improve the accuracy and reliability of analysis.

2. This article introduced the stress sensitivity of permeability, established the seepage control equation in consideration of stress-sensitive permeability, and calculated it. Thus, the typical decline chart under stress sensitivity was obtained.

3. The typical decline chart indicated that stress sensitivity decreased the actual single-well controlled dynamic reserves and the single-well controlled radius. The reason for this phenomenon is that, with the reduction of reservoir pressure, stress sensitivity leads to the lowering of reservoir permeability and the increase in seepage resistance.

4. An sample application was performed according to the established typical decline chart in consideration of the stress sensitivity of permeability and in combination with a certain well in Block Yuan 284 of Changqing Oilfield. The analysis method based on this chart can effectively predict the dynamic reserves and evaluate the characteristic parameters of the reservoirs. 


\section{CONFLICT OF INTEREST}

The authors confirm that this article content has no conflict of interest.

\section{ACKNOWLEDGMENTS}

This work is supported by the National Natural Science Foundation of China (Grant No. 51604287, 51490652).

\section{REFERENCES}

[1] R.W. Bentley, "Global oil \& gas depletion: an overview", Energy Policy, vol. 30, no. 3, pp. 189-205, 2002. [http://dx.doi.org/10.1016/S0301-4215(01)00144-6]

[2] S. Sorrell, J. Speirs, J.R. Bentley, A. Brandt, and R. Miller, "Global oil depletion: A review of the evidence", Energy Policy, vol. 38, no. 9, pp. $5290-5295,2010$ [http://dx.doi.org/10.1016/j.enpol.2010.04.046]

[3] S.A. Holditch, "Tight gas sands", SPE Journal of Petroleum Technology, vol. 58, no. 6, pp. 86-93, 2006. [http://dx.doi.org/10.2118/103356-JPT]

[4] F.O. Jones, and W.W. Owens, "A laboratory study of low-permeability gas sands", SPE Journal of Petroleum Technology, vol. 32, no. 9, pp. $1631-1640,1980$ [http://dx.doi.org/10.2118/7551-PA]

[5] J. Vairogs, C.L. Hearn, D.W. Dareing, and V.W. Rhoades, "Effect of rock stress on gas production from low-permeability reservoirs", SPE Journal of Petroleum Technology, vol. 23, no. 9, pp. 1161-1167, 1971. [http://dx.doi.org/10.2118/3001-PA]

[6] L. Wang, H. Liu, S. Zhen, X. Liu, J. Li, and Y. Song, "Research on quantitative interpretation for stress sensitivity of low-permeability reservoir", Acta Petrolei Sinica, vol. 30, no. 01, pp. 96-99, 2009.

[7] C. Jiao, S. He, Q. Xie, D. Gu, H. Zhu, L. Sun, and H. Liu, "Experiment for stress sensitivity of ultra-low permeability sandstone reservoir", Acta Petrolei Sinica, vol. 32, no. 3, pp. 489-494, 2011.

[8] L. Zhu, Y. Ji, T. Yang, and X. Li, "Analysis on production of coal bed methane considering the change in permeability of coal rock", Open Petroleum Engineering Journal, vol. 9, pp. 289-298, 2016 [http://dx.doi.org/10.2174/1874834101609010289]

[9] S. Wang, Research on Predication Method for Dynamic Reserves of Low-permeability Gas Reservoir., China University of Petroleum (Beijing): Beijing, 2009.

[10] W. Wang, P. Shen, X. Ma, L. Fan, and J. Tang, "Determination of dynamic reserves for heterogeneous complicated low-permeability gas reservoir", Natural Gas Industry, vol. 24, no. 07, pp. 80-82, 2004.

[11] Y. Hao, and X. Xu, "Correct calculation of dynamic reserves for low-permeability gas reservoir", Acta Petrolei Sinica, vol. 29, no. 5, pp. 66-68, 2002.

[12] D. Ilk, J.A. Rushing, and T.A. Blasingame, "Integration of production analysis and rate-time analysis via parametric correlations -- theoretical considerations and practical applications", Proceeding of SPE Hydraulic Fracturing Technology Conference, , 2011 [http://dx.doi.org/10.2118/140556-MS]

[13] C.L. Cipolla, E. Lolon, J. Erdle, and V. Tathed, "Modeling well performance in Shale-Gas Reservoirs", Proceeding of SPE/EAGE Reservoir Characterization and Simulation Conference, Society of Petroleum, Engineers, Abu Dhabi, UAE, 2009.

[http://dx.doi.org/10.2118/125532-MS]

[14] V.M. Dobynin, "Effect of overburden pressure on some properties of sandstones", SPE Journal, vol. 2, no. 4, pp. 360-366, 1962. [http://dx.doi.org/10.2118/461-PA]

[15] T.A. Blasingame, T.L. McCray, and W.J. Lee, "Decline curve analysis for variable pressure drop/variable flowrate systems", In: Proceeding of SPE Gas Technology Symposium, Society of Petroleum Engineers: Houston, Texas, 1991. [http://dx.doi.org/10.2118/21513-MS]

[16] J. Palacio, and T. Blasingame, "Decline curve analysis using type curves: analysis of gas well production data", In: Proceeding of SPE Joint Rocky Mountain Regional and Low Permeability Reservoirs Symposium, Society of Petroleum Engineers: Denver, USA, 1993. [http://dx.doi.org/10.2118/25909-MS]

[17] M.J. Fetkovich, "Decline curve analysis using type curves", SPE Journal of Petroleum Technology, vol. 32, no. 06, pp. 1065-1077, 1980. [http://dx.doi.org/10.2118/4629-PA]

[18] M. Fetkovich, M. Vienot, M. Bradley, and U.G. Kiesow, "Decline curve analysis using type curves: case histories", SPE Formation Evaluation, vol. 2, no. 4, pp. 637-656, 1987. [http://dx.doi.org/10.2118/13169-PA]

[19] D. Yin, D. Wang, C. Zhang, and Y. Duan, "Shale gas productivity predicting model and analysis of influence factor", Open Petroleum Engineering Journal, vol. 8, pp. 203-207, 2015. [http://dx.doi.org/10.2174/1874834101508010203] 
[20] O.A. Pedrosa, "Pressure transient response in stress-sensitive formations", Proceeding of SPE California Regional Meeting, , 1986 [http://dx.doi.org/10.2118/15115-MS]

\section{(C) 2017 Shen et al.}

This is an open access article distributed under the terms of the Creative Commons Attribution 4.0 International Public License (CC-BY 4.0), a copy of which is available at: https://creativecommons.org/licenses/by/4.0/legalcode. This license permits unrestricted use, distribution, and reproduction in any medium, provided the original author and source are credited. 